\title{
Temperature rises in dispute over costing climate change
}

London. Sir Crispin Tickell, one of the British government's leading advisers on environmental policy, has stepped into a fierce controversy about a United Nations (UN) report on the social and economic dimensions of climate change by suggesting that the use of cost-benefit analysis in a key chapter of the report is inappropriate.

Tickell, formerly Britain's ambassador to the UN, is now warden of Green College, Oxford. The author of a book on climate change, he made the comments in an exchange of letters with David Pearce, director of the Centre for Social and Economic Research on the Global Environment at University College, London, and one author of the forthcoming Second Assessment Report of the UN's Intergovernmental Panel on Climate Change (IPCC).

Tickell says cost-benefit analysis "should not be the basis - still less the sole basis for making policy". But Pearce says Tickell's remarks are "wholly out of step" with government policy. "Being alone does not make you wrong," writes Pearce, a lead author of Chapter 6 of the section of the report prepared by IPCC's working group III. "But it ought to make you wonder if you have the basis for making such a judgement."

Tickell appears to disagree with the decision of the authors of Chapter 6 to use a technique for placing a value on loss of life whose implications are to assign a value in a developing country

of one-fifteenth the

value in the developed world, as it is based on a country's capability to pay for reduced risk. He describes the results of this method of calcula-

tion, known as Tickell: criticizes use of 'value of statistical cost-benefit analysis. life', as 'economists' artefacts of doubtful value and subjective character, with almost unlimited capacity to mislead".

But Pearce, questioning Tickell's understanding of the techniques of cost-benefit analysis, says developing countries cannot pay the same as the higher-income developed world. "The resources have to come from somewhere," he writes. "If, for example, they come from reduced foreign aid, we may kill more people than we save."

Pearce cites the lack of published literature exploring the impact of equal value statistical lives - an alternative method for placing a value on life - as another reason for not using Tickell's ideas as the basis for calculations in Chapter 6. "Our remit was to describe what the literature says, not to rewrite it, nor do original research."

The exchange is likely to add fuel to the debate already raging about the methodology used by the authors of Chapter 6 to estimate damage from climate change. The debate has pitted the authors against government delegates to the IPCC, and divided the environmentalist movement over calls from one group, the Global Commons Institute in London, that the chapter should be withdrawn (see Nature 378, 119; 1995).

One author has suggested that this should be done on the grounds that a summary designed for policy-makers and written by a team of experts from different governments appeared to contradict the chapter. The summary does not contain quantitative damage estimates, on the grounds that such values are subjective. This author now appears to have withdrawn his objections. And the IPCC says the chapter will be included in the Second Assessment Report due to be approved in Rome next week.

However, a letter in this issue of Nature (see page 433), signed by 38 scientists including Sir Martin Rees, Britain's Astronomer Royal, and Hans Peter Duerr, director of the Max Planck Institute of Physics, says the chapter must go, on the grounds that a summary contradicting the chapter's contents violates IPCC procedures.

But not all environmentalist groups agree with this stance. The Climate Action Network, an alliance of green groups working in the field of climate policy, says this single issue should not be allowed to obstruct the greater goal of limiting the harmful effects of climate change. The chapter contains "a lot of information relevant to policy-makers", says Bill Hare, a climate policy adviser with Greenpeace International.

Hare also says the Second Assessment Report will not be the last word. The report will be discussed at a meeting of the Subsidiary Body on Scientific, Technical and Technological Cooperation before it is put to the Conference of Parties. Omitting Chapter 6 before it is even published, "would destroy the IPCC's integrity as an impartial body and open the way for vested interests to interfere", adds Hare

P. R. Shukla, professor of management sciences at the Indian Institute of Management at Ahmedabad and a lead author for Chapters 8,9 and 10 of the report, agrees. "We must not throw the baby out with the bath water," he says. But Shukla, whose chapters calculate the costs of slowing down greenhouse gas emissions, says the IPCC should arrange an interim review - "perhaps a supplement to the second assessment report" that takes notice of more recent literature from the developing world. Ehsan Masood
Call for more research into health effects of Chernobyl accident

London. The World Health Organization (WHO) last week called on scientists to step up their research into the effects of the Chernobyl nuclear accident that took place almost a decade ago in Ukraine in the former Soviet Union.

The call came during a four-day international conference on the effects on health of the accident. Speaking on the last day of the meeting in Geneva, sponsored by WHO and attended by 600 delegates from 59 countries, Wilfried Kreisel, WHO's executive director in charge of health and environment, said WHO "would want to see the volume and quality of medical assistance and scientific research increased".

Kreisel added that the scientific community would be doing a "disservice" if it failed to extract benefits for mankind out of "this monumental human tragedy".

But some scientists claim any apparent slowing down in research on the impact of the accident should be blamed not on 'Chernobyl fatigue' in the scientific community but on the unreliability of Russian data and on the large evacuation programme after the accident.

Last week's meeting heard evidence of an increasing number of incidents of psychological disorder among workers who dealt with the accident and its aftermath, as well as among those who moved away from areas of high contamination. Delegates were also told of an increase in thyroid cancers among children, but of "no statistically measurable increase in leukaemia".

Much of this information has been known for some time (see, for example, Nature 375,365 ; 1995). But the identity of the radioactive agents responsible for increases in the incidence of thyroid cancer in children remains unclear. WHO acknowledges that identifying the agent should be a priority. Iodine 131 is one suspect, but when used in medicine it has not been shown to cause thyroid cancer.

WHO has begun to address some of the problems through its recently created Radiation Emergency Medical Preparedness and Assistance Network (REMPAN). The organization is also establishing a separate Chernobyl-related project in $\mathrm{St}$ Petersburg, Russia, to deal with problems encountered by accident recovery workers, and has called for more humanitarian aid for the region.

According to several delegates to the meeting, one useful outcome was agreement that the Soviet authorities, despite criticism from the West - caused largely by the obsessive secrecy of the Soviet regime "did a pretty good job of treating the casualties".

E. M. 